\title{
LEVANTAMENTO DA DISPERSÃO E VARIABILIDADE GENÉTICA DE Tectococcus ovatus (HETEROPTERA: ERIOCOCCIDAE) NAS REGIÕES DE OCORRÊNCIA NATURAL DE Psidium cattleianum (MYRTACEAE)
}

\author{
Luciene Erica Cordeiro Ranuci ${ }^{1}$, Josiane de Carvalho Vitorino ${ }^{2}$, Tracy Johnson ${ }^{3}$, Marcelo Diniz Vitorino ${ }^{4}$ \\ ${ }^{1}$ Eng. Florestal, M.Sc., Programa de Pós-Graduação em Eng. Ambiental, FURB, Blumenau, SC, Brasil - luranuci@ yahoo.com.br \\ ${ }^{2}$ Farmacêutica, Dra ${ }^{\text {., }}$ Curso de Farmácia, UNIVALI, Itajaí, SC, Brasil - jvitorino@univali.br \\ ${ }^{3} \mathrm{Dr}^{\mathrm{a}}$., Institute of Pacific Islands Forestry, USDA Forest Service, Hawaii, USA - tracyjohnson @ fs.fed.us \\ ${ }^{4}$ Eng. Florestal, Dr., Depto. de Engenharia Florestal, FURB, Blumenau, SC, Brasil - diniz@ furb.br \\ Recebido para publicação: 26/04/2011 - Aceito para publicação: 05/10/2012
}

\begin{abstract}
Resumo
A espécie Psidium cattleianum é considerada uma das maiores ameaças ao ecossistema e à biodiversidade nas ilhas do Havaí. Buscando controlar sua disseminação, adotaram-se técnicas de controle biológico. Dentre as várias espécies estudadas como agente de controle, Tectococcus ovatus (Heteroptera: Eriococcidae) apresentou o maior nível de especificidade. Este trabalho teve como objetivo verificar a existência de variabilidade genética entre e dentro das diferentes populações de Tectococcus ovatus amostradas, utilizando a técnica de PCR-RAPD. As análises foram realizadas a partir de fêmeas coletadas nos estados do Rio de Janeiro, Paraná, Santa Catarina e Rio Grande do Sul. Dos oito iniciadores de PCR-RAPD testados, quatro foram utilizados nas análises, revelando marcadores monomórficos e polimórficos com uma freqüência variável, tanto para os indivíduos de uma mesma localidade quanto para os indivíduos de localidades diferentes. Através da análise de agrupamento de caracterização molecular, foi possível verificar a formação de dois grupos distintos, A e B, apresentando uma variabilidade genética de $44 \%$. Os resultados obtidos através da análise dos marcadores RAPD foram úteis na verificação de variação e forneceram informações sobre os níveis de variabilidade e similaridade entre e dentro das diferentes populações de Tectococcus ovatus.

Palavras-chave: Controle biológico; variabilidade genética; PCR-RAPD.
\end{abstract}

\begin{abstract}
Survey of dispersal and genetic variability of Tectococcus ovatus (Heteroptera: Eriococcidae) in the regions of natural occurence of Psidium cattleianum (Myrtaceae). The species Psidium cattleianum is considered one of the greatest threats to the ecosystem and biodiversity of the islands from Hawaii. Seeking to control its dissemination, techniques of biological control were used. Among the various species studied, as a biological control agent, Tectococcus ovatus showed a higher level of specificity. This work had as its aim to verify the existence of genetic variability among and inside different populations of Tectococcus ovatus sampled, using the technique of PCR-RAPD. The analyses were made from females collected in the states of Rio de Janeiro, Paraná, Santa Catarina and Rio Grande do Sul. From the eight initiators of PCR-RAPD tested, four were used in the analyses, revealing monomorphic and polimorphic markers with a variable frequency, to the individuals of one place as well as to the individuals of different places. Through the analysis of the grouping of molecular characterization it was possible to verify a formation of two distinctive groups A and B, presenting a genetic variability of $44 \%$. The results obtained through the analysis of RAPD markers were useful to variation verification and provided safe information about the levels of variability and similarity amongst and inside the different populations of Tectococcus ovatus.

Keywords: Biological control; genetic variability; PCR-RAPD.
\end{abstract}

\section{INTRODUÇÃO}

A invasão por espécies exóticas vem sendo considerada um grande problema mundial, pois, em alguns casos, coloca em risco o equilíbrio dos ecossistemas, podendo inclusive causar perdas irreversíveis à biodiversidade. 
Uma espécie passa a ser considerada exótica invasora quando introduzida em um novo ambiente e encontra condições favoráveis ao seu desenvolvimento. Fatores climatológicos e pedológicos acrescidos da ausência de inimigos naturais darão a essa espécie uma grande vantagem competitiva em relação às espécies nativas, tendendo a se tornar dominante em seu novo hábitat. O resultado dessa nova situação pode ser um ecossistema em desequilibro, com consequências provavelmente desastrosas para a região infestada.

$\mathrm{O}$ araçazeiro, Psidium cattleianum Sabine (Myrtaceae) é considerado atualmente, uma das maiores ameaças ao ecossistema natural e à biodiversidade nas ilhas do Havaí. Ao longo dos anos, passou a se comportar como invasora nesses ecossistemas, causando severos distúrbios ambientais. Possui várias características de invasora, mas aparentemente a reprodução vegetativa da raiz de forma clonal é o maior responsável pelo seu sucesso, dominando florestas naturais no arquipélago do Havaí (TUNISON, 1991).

Essa espécie é nativa da Floresta Atlântica, ocorrendo primariamente ao longo da Costa Atlântica na porção leste da América do Sul, estendendo-se do Espírito Santo até o Uruguai (LEGRAND; KLEIN, 1977).

Na tentativa de controlar sua disseminação, o governo do Havaí buscou algumas alternativas, passando do controle químico aos tratos culturais, não obtendo resultados razoáveis em função da fácil adaptação da espécie, sua grande área de abrangência e capacidade de recuperação. Baseado no êxito de experiências na área de controle biológico de plantas invasoras realizadas por alguns países, concluiu-se que esta seria a técnica mais eficaz e com menor risco à flora nativa.

Para Vitorino et al. (2000), o controle biológico de plantas é uma alternativa mais duradoura que outros métodos e preenche vários requisitos, principalmente ambientais e econômicos.

Entre os insetos estudados no decorrer de vários anos, Tectococcus ovatus Hempel (Heteroptera: Eriococcidae) foi considerado o mais recomendado como potencial agente de controle biológico contra o araçazeiro, devido a seu elevado nível de especificidade, o que resulta em grande impacto na planta hospedeira (SMITH et al., 2002; VITORINO, 1995).

Buscando associar controle biológico e biologia molecular, o presente trabalho consiste na utilização de marcadores moleculares com capacidade de detectar variabilidade genética, tendo como objetivo encontrar características específicas no DNA genômico entre e dentro das diferentes populações de T. ovatus, que demonstrem uma maior capacidade em causar danos ou uma maior adaptabilidade dele a determinada procedência de Psidium cattleianum, promovendo assim um controle biológico mais eficiente, baixando consideravelmente a população da planta.

No caso de $T$. ovatus, a identificação é necessária para verificar se existe uma adaptação ou dependência a procedências específicas de $P$. cattleianum ou se esse agente ataca de forma aleatória, desconsiderando a procedência da planta.

A aplicação de técnicas de biologia molecular para caracterização genética de populações de espécies invasoras e agentes de controle biológico proporciona oportunidades mais precisas para encontrar um "correspondente biótipo" e para conhecer o histórico da introdução de espécies invasoras (WILLIANS et al., 2005).

O estudo de variabilidade genética nas populações de T. ovatus foi realizado utilizando a técnica de RAPD (DNA polimórfico amplificado ao acaso). Essa técnica tem permitido estudos de polimorfismos, demonstrando ser uma ferramenta eficiente para responder questões relacionadas à distribuição da variabilidade genética dentro e entre populações de insetos.

\section{MATERIAS E MÉTODOS}

\section{Áreas de coleta}

As coletas das fêmeas de Tectococcus ovatus associadas a Psidium cattleianum concentraram-se em municípios dos estados do Rio de Janeiro, Paraná, Santa Catarina e Rio Grande do Sul, no período de abril de 2006 a julho de 2008.

No Paraná, as fêmeas foram extraídas exclusivamente de folhas de Psidium ovale (Spreng) (Myrtaceae) coletadas e utilizadas nos ensaios a fim de se buscar mais informações dessa associação e verificar a existência de um padrão genético diferente do encontrado nas fêmeas, que estão associadas ao araçazeiro - Psidium cattleianum.

No Rio de Janeiro, Santa Catarina e Rio Grande do Sul, as coletas de P. cattleianum foram realizadas em municípios litorâneos, onde a vegetação é caracterizada como Floresta Ombrófila Densa de 
Terras Baixas (Restinga), típicas da Mata Atlântica, situada a uma altitude de 0,8-20 metros em relação ao nível do mar (NASCIMENTO; SILVA, 2004; SILVA; COSTA, 2009).

\section{Amostragem}

Noventa e três fêmeas de Tectococcus ovatus foram utilizadas nos ensaios em laboratório, sendo que, desse número, setenta e três foram extraídas de folhas de Psidium cattleianum e vinte extraídas de folhas de Psidium ovale (Tabela 1).

Tabela 1. Locais de coleta e quantidade de amostras de galhas de Tectococcus ovatus Hempel (Heteroptera: Eriococcidae), agente galhador de Psidium cattleianum Sabine e Psidium ovale (Spreng) (Myrtaceae), no período de abril de 2006 a julho de 2008.

Table 1. Collection sites and quantities of galls samples of Tectococcus ovatus Hempel (Heteroptera: Eriococcidae), gall maker of Psidium cattleianum Sabine and Psidium ovale (Spreng) (Myrtaceae) between april 2006 and july 2008.

\begin{tabular}{|c|c|c|c|c|c|c|}
\hline \multirow{2}{*}{ Data } & \multirow{2}{*}{ Estado } & \multirow{2}{*}{ Município } & \multirow{2}{*}{$\begin{array}{c}\text { Planta } \\
\text { hospedeira }\end{array}$} & \multicolumn{3}{|c|}{ Indivíduos } \\
\hline & & & & Coleta & Código & Analisados \\
\hline 04.04 .06 & $\mathrm{SC}$ & Sombrio & P.c. & 33 & A8 & 9 \\
\hline 04.04 .06 & $\mathrm{SC}$ & Sombrio & P.c. & 35 & A9 & 9 \\
\hline 05.04 .06 & $\mathrm{SC}$ & Sombrio & P.c. & 36 & A10 & 9 \\
\hline 07.04 .06 & $\mathrm{RS}$ & Tramandaí & P.c. & 52 & A11 & 9 \\
\hline 07.04 .06 & $\mathrm{RS}$ & Tramandaí & P.c. & 41 & A12 & 9 \\
\hline 08.04 .06 & $\mathrm{RS}$ & Tramandaí & P.c. & 4 & A13 & 4 \\
\hline 04.12 .06 & PR & $\begin{array}{c}\text { Piraquara - Mananciais da } \\
\text { Serra }\end{array}$ & P.o. & 16 & A15 & 10 \\
\hline 04.12 .06 & PR & $\begin{array}{c}\text { Piraquara - Mananciais da } \\
\text { Serra }\end{array}$ & P.o. & 12 & A16 & 5 \\
\hline 04.12 .06 & PR & $\begin{array}{c}\text { Piraquara - Mananciais da } \\
\text { Serra }\end{array}$ & P.o. & 8 & A17 & 5 \\
\hline 20.01 .07 & $\mathrm{SC}$ & Baln. Camboriú - Estaleiro & P.c. & 20 & A14 & 9 \\
\hline 10.03.07 & $\mathrm{RJ}$ & Quissamã & P.c. & 3 & A18 & 3 \\
\hline 11.03 .07 & RJ & $\begin{array}{c}\text { Campos dos Goytacazes - } \\
\text { Farol de S. Tomé }\end{array}$ & P.c. & 4 & A19 & 2 \\
\hline 15.07 .08 & RJ & $\begin{array}{c}\text { Campos dos Goytacazes - } \\
\text { Farol de S. Tomé }\end{array}$ & P.c. & 77 & A20 & 10 \\
\hline \multicolumn{4}{|c|}{ Total de indivíduos coletados e analisados } & 341 & & 93 \\
\hline
\end{tabular}

P.c.: Psidium cattleianum Sabine; P.o.: Psidium ovale (Spreng) (Myrtaceae)

\section{PCR-RAPD}

As análises foram realizadas objetivando encontrar variabilidade genética entre e dentro das populações de Tectococcus ovatus, utilizando para isso fêmeas extraídas de galhas das espécies Psidium cattleianum e Psidium ovale.

\section{Extração do DNA}

A extração do DNA foi realizada segundo protocolo de Cheung et al. (1993), com modificações.

As fêmeas adultas de Tectococcus ovatus foram maceradas individualmente em tubo de microcentrífuga de 1,5 ml em $160 \mu \mathrm{l}$ de solução tampão de extração (200 $\mu \mathrm{l}$ Tris-HCl pH 8.0, $140 \mu \mathrm{l}$ EDTA, $400 \mu \mathrm{l} \mathrm{NaCl}$ e $260 \mu \mathrm{l}$ água) e $20 \mu \mathrm{l}$ de SDS (dodecil sulfato de sódio). A solução foi homogeneizada e incubada por 1 hora a $60^{\circ} \mathrm{C}$. Ao final desse procedimento, foram acrescidos $30 \mu \mathrm{l}$ de clorofórmio à solução, centrifugada por 5 minutos a $13.000 \mathrm{rpm}$. O sobrenadante foi retirado e transferido para novos tubos, adicionando-se $100 \mu \mathrm{l}$ de acetato de amônia e $450 \mu \mathrm{l}$ de etanol 96\%. Após 15 minutos de centrifugação, o sobrenadante foi descartado e o precipitado lavado com $500 \mu$ de etanol $70 \%$.

As amostras foram centrifugadas novamente por 5 minutos e o sobrenadante descartado. Essas amostras foram secas em estufa a $50^{\circ} \mathrm{C}$. Após estarem completamente secas, as amostras de DNA foram ressuspendidas em $20 \mu \mathrm{l}$ de água ultrapurificada estéril. 
A concentração e a pureza do DNA de cada uma das amostras foram determinadas através da leitura de absorbância em $260 \mathrm{~nm}$ em $280 \mathrm{~nm}$ referente à quantificação de proteínas, em espectrofotômetro.

\section{Reação de amplificação}

As reações de amplificação PCR-RAPD foram conduzidas em um volume final de $15 \mu \mathrm{l}$, contendo 1,5 $\mu \mathrm{l}$ de solução tampão, $0,6 \mu \mathrm{l}$ de $\mathrm{MgCl}_{2}, 0,6 \mu \mathrm{l}$ de dNTP, $0,1 \mu \mathrm{l}$ de Taq DNA polimerase, 2,0 $\mu \mathrm{l}$ de cada um dos iniciadores, $1,0 \mu \mathrm{l}$ de DNA genômico e água ultrapurificada estéril.

As amplificações foram realizadas em termociclador Thermocycler (Eppendorf), programado para um 1 ciclo, para desnaturação inicial a $95{ }^{\circ} \mathrm{C}$ por 5 minutos, 37 ciclos para anelamento a $94{ }^{\circ} \mathrm{C}$ por 45 segundos, $37^{\circ} \mathrm{C}$ por 1 minuto e 30 segundos, $72{ }^{\circ} \mathrm{C}$ por 2 minutos e 30 segundos e, para finalizar, 1 ciclo para polimerização a $72{ }^{\circ} \mathrm{C}$ por 3 minutos. Para verificar a presença de possíveis contaminantes, controles negativos foram incluídos.

Dos oito iniciadores de sequência curta (OPL, OPM, OPB-6, OPB-15, OPA-4, 23L, OPB-17, P1254) testados para conduzir as reações PCR-RAPD de Tectococcus ovatus em Psidium cattleianum e $P$. ovale, apenas quatro (OPB-15, 23L, OPB-6 e OPM) foram utilizados nos ensaios, por apresentarem um padrão nítido de bandas e presença de bandas polimórficas. Os iniciadores foram descritos por LIN et al. (1996).

Os produtos das amplificações do DNA foram fracionados em gel de agarose 1,5\% em $180 \mathrm{ml}$ de tampão TBE 1X (Tris $40 \mathrm{mM}$, ácido bórico $89 \mathrm{mM}$, EDTA 2,5 mM), a 5V/cm durante 3 horas, e corados com solução de brometo de etídio $(0,5-1 \mu \mathrm{g} / \mathrm{ml})$ por 20-30 minutos. O tamanho dos fragmentos foi determinado comparando-se a distância migrada por eles com as bandas geradas por um marcador padrão de peso molecular $1 \mathrm{~kb}$ DNA Ladder (Invitrogen). A visualização dos fragmentos foi realizada sob luz ultravioleta em transluminador UVP Basic Imaging Systems.

\section{Análise dos resultados}

Os fragmentos de RAPD amplificados e separados por eletroforese em gel foram analisados de acordo com a presença (1) ou ausência (0) de cada banda em cada indivíduo, formando uma matriz de dados binários.

A matriz de similaridade foi construída utilizando-se o coeficiente de JACCARD (1908), $S_{x y}=a /(a+b+c)$ em $\mathrm{x}$, mas ausentes em y; $\mathrm{c}=$ número de bandas presentes em $\mathrm{y}$, mas ausentes em $\mathrm{x}$.

Após a estimativa da similaridade genética entre os indivíduos, foi gerado um dendrograma utilizando-se o algoritmo UPGMA (agrupamento por médias não ponderadas) (WEIR, 1990). A matriz de similaridade e o dendrograma foram calculados utilizando-se o programa NTSYS-PC (Numerical Taxonomy and Multivariate Analysis System) versão 2.0 (ROHLF, 1992).

\section{RESULTADOS E DISCUSSÕES}

A análise de variabilidade genética entre as amostras das diferentes populações de Tectococcus ovatus foi conduzida pela técnica de PCR-RAPD, revelando um grande número de marcadores monomórficos e polimórficos com uma frequência variável, tanto para os indivíduos de uma mesma localidade quanto para os indivíduos de localidades diferentes.

Os resultados obtidos neste trabalho, por meio da análise dos marcadores RAPD, foram úteis na verificação de variação e forneceram informações seguras sobre os níveis de variabilidade e similaridade entre e dentro das diferentes populações de T. ovatus.

Os marcadores de frequência variável apresentados revelaram um baixo nível de polimorfismo dentro e entre as diferentes populações. O polimorfismo apresentado em T. ovatus foi considerado insuficiente para se afirmar que existe um padrão genético diferenciado entre as diferentes populações. $\mathrm{O}$ alto nível de similaridade demonstra que os insetos coletados nas diferentes regiões do Brasil podem ser utilizados para o controle biológico de qualquer procedência de Psidium cattleianum introduzida no Havaí, não sendo necessário associar a origem do inseto com a origem da planta. 
Dos oito iniciadores testados para conduzir as reações de amplificação, apenas OPB-15, 23L, OPB-6 e OPM foram utilizados nas análises, por apresentarem um alto padrão de intensidade de bandas, reprodutibilidade e maior número de bandas polimórficas. O número de fragmentos amplificados foi diferente para cada iniciador e para cada localidade analisada, e estão representados nas figuras de 1 a 4 . Esses iniciadores geraram 26 marcadores, sendo que, destes, 25 apresentaram polimorfismo (96\%) com fragmentos de peso molecular variando de $280 \mathrm{pb}$ a $2.114 \mathrm{pb}$.

Foi possível observar uma frequência variável de polimorfismo (50\%) nos quatro iniciadores utilizados nas análises de amplificação de Tectococcus ovatus. O iniciador OPB-6 apresentou marcadores com $45 \%$ de polimorfismo, enquanto o iniciador $23 \mathrm{~L}$ apresentou um polimorfismo de $56 \%$. Já os iniciadores OPB-15 e OPM apresentaram marcadores com uma frequência aproximada de 50\%.

Dois marcadores do iniciador 23L com pesos moleculares de $306 \mathrm{pb}$ e $445 \mathrm{pb}$ foram constantes em todos os indivíduos analisados, podendo então ser classificados como marcadores moleculares espécie-específicos. Já os outros marcadores tiveram uma participação variável nas amplificações.

As amplificações dos marcadores de pesos moleculares $643 \mathrm{pb}(23 \mathrm{~L}), 679 \mathrm{pb}(23 \mathrm{~L}), 858 \mathrm{pb}$ (23L), 900 pb (OPB-15) e 1000-2 pb (OPB-6) apresentaram um polimorfismo acima de $80 \%$.

É possível verificar polimorfismo de baixa intensidade representado pela amplificação de um único marcador (1500-3 pb) do iniciador OPB-6 exclusivo ao indivíduo (A20-72), proveniente do Rio de Janeiro.

O marcador de peso molecular 1000-2 pb (OPB-6) amplificou para praticamente todos os indivíduos analisados, exceto para os indivíduos A20-7, A20-33, A20-72, do Rio de Janeiro, e para o indivíduo A10-5, de Santa Catarina.

O marcador de peso molecular $858 \mathrm{pb}$ (23L) também teve uma alta porcentagem de amplificação dos indivíduos, com exceção dos indivíduos A8-2, A10-10 de Santa Catarina, A12-5 do Rio Grande do Sul e do indivíduo A16-5 do Paraná.

Os marcadores de pesos moleculares $1070 \mathrm{pb}, 1214 \mathrm{pb}$ e $1286 \mathrm{pb}$ do iniciador 23L mostraram-se exclusivos para caracterização específica de todos os indivíduos do Rio de Janeiro.

$\mathrm{Na}$ análise de agrupamento dos indivíduos (Tabela 2), é possível observar a formação de dois grupos distintos, A e B, com uma variabilidade genética de $44 \%$ (=56\% similaridade). O grupo A é formado exclusivamente por indivíduos provenientes do Rio de Janeiro, apresentando uma variabilidade de $25 \%$ entre eles $(=75 \%$ similaridade $)$.

O grupo B é formado pelos indivíduos das diferentes localidades do Paraná, Santa Catarina e Rio Grande do Sul, apresentando uma variabilidade genética de 32\% (=68\% similaridade), e pode ser subdividido em dois subgrupos, B1 e B2.

O subgrupo B1 é formado apenas por um indivíduo de Santa Catarina (amostra A10-5), apresentando uma variabilidade genética de $32 \%$ em relação aos demais.

O subgrupo B2 é formado por todos os demais indivíduos, apresentando uma variabilidade genética de 31\% (= 69\% similaridade), podendo ainda ser subdividido em B2.1 e B2.2.

O B2.1 é formado por três indivíduos de uma mesma localidade no Paraná (A15-3, A15-5, A156), um indivíduo do Rio Grande do Sul (A13-3) e oito indivíduos de diferentes localidades de Santa Catarina (A8-2, A9-8, A10-6, A10-7, A14-2, A14-7, A14-8, A14-9).

Os indivíduos de Santa Catarina apresentaram uma baixa variabilidade genética (11\%), sendo, ainda, que os indivíduos A14-2 e A14-8 apresentaram-se idênticos.

Foi possível observar que os indivíduos de Santa Catarina isolaram-se dos demais no subgrupo B2.1, com exceção dos indivíduos A14-1 e A14-6, que ficaram no B2.2.

O subgrupo B2.2 apresenta uma variabilidade genética de $24 \%$ (= $76 \%$ similaridade) e é formado por dezoito indivíduos de diferentes localidades do Rio Grande do Sul (A11-2, A11-3, A11-4, A11-5, A11-6, A11-7, A11-9, A11-10, A12-1, A12-2, A12-3, A12-4, A12-5, A12-6, A12-8, A12-9, A13-1, A132), quatorze de diferentes localidades de Santa Catarina (A8-1, A8-3, A8-4, A8-8, A9-1, A9-2, A9-4, A95, A9-9, A10-3, A10-4, A10-10, A14-1 e A14-6) e cinco indivíduos de duas localidades do Paraná (A154, A15-7, A15-9 A16-5 e A17-7).

Observa-se também uma diversidade genética baixa, aproximadamente 5\%, entre os indivíduos coletados entre as diferentes árvores do Rio Grande do Sul e Paraná.

Observa-se ainda, nesse subgrupo, que os indivíduos A11-3 e A11-4 do Rio Grande do Sul são idênticos. 
Tabela 2. Agrupamento dos indivíduos de Tectococcus ovatus obtidos pela análise de agrupamento UPGMA.

Table 2. Grouping of Tectococcus ovatus individuals obtained by UPGMA cluster analysis.

\begin{tabular}{|c|c|c|}
\hline Código amostra & Procedência & Espécie \\
\hline \multicolumn{3}{|c|}{ Grupo A } \\
\hline A20-7 & Farol de São Tomé - RJ & Psidium cattleianum \\
\hline A20-22 & Farol de São Tomé - RJ & Psidium cattleianum \\
\hline A20-23 & Farol de São Tomé - RJ & Psidium cattleianum \\
\hline A20-31 & Farol de São Tomé - RJ & Psidium cattleianum \\
\hline A20-33 & Farol de São Tomé - RJ & Psidium cattleianum \\
\hline A20-39 & Farol de São Tomé - RJ & Psidium cattleianum \\
\hline A20-72 & Farol de São Tomé - RJ & Psidium cattleianum \\
\hline \multicolumn{3}{|c|}{ Grupo B - Subgrupo B1 } \\
\hline A10-5 & Sombrio - SC & Psidium cattleianum \\
\hline \multicolumn{3}{|c|}{ Subgrupo B2 - Subgrupo B2.1 } \\
\hline A8-2 & Sombrio - SC & Psidium cattleianum \\
\hline A9-8 & Sombrio - SC & Psidium cattleianum \\
\hline A10-6 & Sombrio - SC & Psidium cattleianum \\
\hline A10-7 & Sombrio - SC & Psidium cattleianum \\
\hline A13-3 & Tramandaí - RS & Psidium cattleianum \\
\hline A14-2 & Estaleiro - SC & Psidium cattleianum \\
\hline A14-7 & Estaleiro - SC & Psidium cattleianum \\
\hline A14-8 & Estaleiro - SC & Psidium cattleianum \\
\hline A14-9 & Estaleiro - SC & Psidium cattleianum \\
\hline A15-3 & Mananciais da Serra - PR & Psidium ovale \\
\hline A15-5 & Mananciais da Serra - PR & Psidium ovale \\
\hline A15-6 & Mananciais da Serra - PR & Psidium ovale \\
\hline \multicolumn{3}{|c|}{ Subgrupo B2.2 } \\
\hline A8-1 & Sombrio - SC & Psidium cattleianum \\
\hline A8-3 & Sombrio - SC & Psidium cattleianum \\
\hline A8-4 & Sombrio - SC & Psidium cattleianum \\
\hline A8-8 & Sombrio - SC & Psidium cattleianum \\
\hline A9-1 & Sombrio - SC & Psidium cattleianum \\
\hline A9-2 & Sombrio - SC & Psidium cattleianum \\
\hline A9-4 & Sombrio - SC & Psidium cattleianum \\
\hline A9-5 & Sombrio - SC & Psidium cattleianum \\
\hline A9-9 & Sombrio - SC & Psidium cattleianum \\
\hline A10-3 & Sombrio - SC & Psidium cattleianum \\
\hline A10-4 & Sombrio - SC & Psidium cattleianum \\
\hline A10-10 & Sombrio - SC & Psidium cattleianum \\
\hline A11-2 & Tramandaí - RS & Psidium cattleianum \\
\hline A11-3 & Tramandaí - RS & Psidium cattleianum \\
\hline A11-4 & Tramandaí - RS & Psidium cattleianum \\
\hline A11-5 & Tramandaí - RS & Psidium cattleianum \\
\hline A11-6 & Tramandaí - RS & Psidium cattleianum \\
\hline A11-7 & Tramandaí - RS & Psidium cattleianum \\
\hline A11-9 & Tramandaí - RS & Psidium cattleianum \\
\hline A11-10 & Tramandaí - RS & Psidium cattleianum \\
\hline A12-1 & Tramandaí - RS & Psidium cattleianum \\
\hline A12-2 & Tramandaí - RS & Psidium cattleianum \\
\hline A12-3 & Tramandaí - RS & Psidium cattleianum \\
\hline A12-4 & Tramandaí - RS & Psidium cattleianum \\
\hline A12-5 & Tramandaí - RS & Psidium cattleianum \\
\hline A12-6 & Tramandaí - RS & Psidium cattleianum \\
\hline
\end{tabular}




\begin{tabular}{lcc}
\hline A12-8 & Tramandaí - RS & Psidium cattleianum \\
A12-9 & Tramandaí - RS & Psidium cattleianum \\
A13-1 & Tramandaí - RS & Psidium cattleianum \\
A13-2 & Tramandaí - RS & Psidium cattleianum \\
A14-1 & Estaleiro - SC & Psidium cattleianum \\
A14-6 & Estaleiro - SC & Psidium cattleianum \\
A15-4 & Mananciais da Serra - PR & Psidium ovale \\
A15-7 & Mananciais da Serra - PR & Psidium ovale \\
A1 5-9 & Mananciais da Serra - PR & Psidium ovale \\
A16-5 & Mananciais da Serra - PR & Psidium ovale \\
A17-7 & Mananciais da Serra - PR & Psidium ovale \\
\hline
\end{tabular}

Devido ao baixo nível de intensidade das bandas e à ausência de produtos de amplificação, muitos marcadores e indivíduos foram excluídos e não puderam ser comparados entre as amostras presentes nos diferentes géis, sendo assim desconsiderados para a construção da matriz de similaridade. Dos 93 indivíduos testados para cada iniciador nas três repetições realizadas, apenas 57 foram utilizados para comparação entre amostras através da análise de agrupamento, por apresentarem resultados confiáveis.

Pela análise dos resultados obtidos na matriz de dados binários, observou-se uma variação na frequência dos marcadores formada com os quatro iniciadores. É possível encontrar marcadores presentes em todos os indivíduos, como também marcadores que amplificaram em menos de 10 indivíduos em um total de 57. Mas para a grande maioria dos marcadores formados é possível afirmar que eles contribuíram para revelar polimorfismo em pelo menos metade dos indivíduos analisados.

Pelos resultados apresentados, é possível observar que, entre os iniciadores utilizados, o 23L apresenta o maior índice de marcadores polimórficos, 56\%. Os outros iniciadores apresentam um polimorfismo variando de $45 \%$ (OPB-6) a 50\% (OPB-15 e OPM).

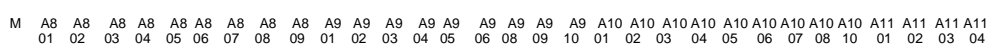

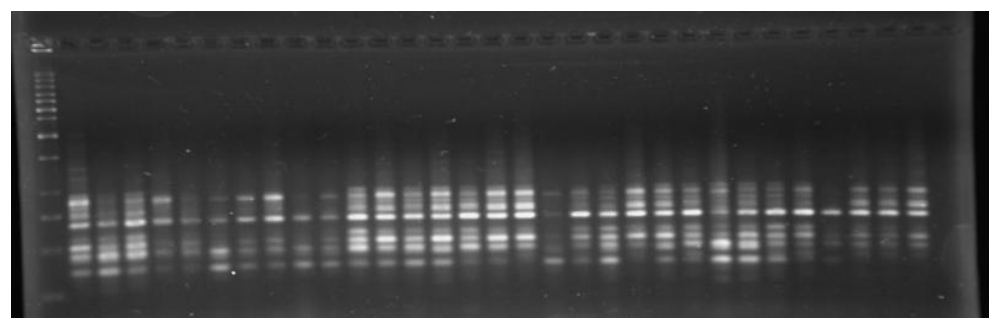

M A11 A11 A11 A11 A11 A12 A12 A12 A12 A12 A12 A12 A12 A12 A13 A13 A13 A13 A14 A14 A14 A14 A14 A14 A14 A14 A14 A15 A15 A15 A15

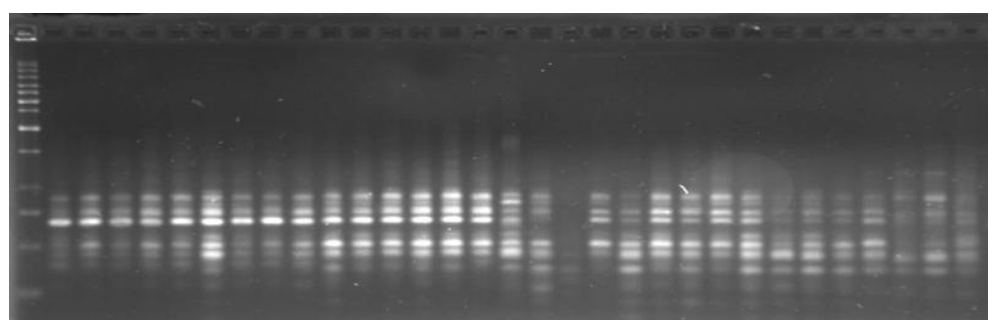

Figura 1. Padrão dos fragmentos amplificados por meio de PCR-RAPD em indivíduos de Tectococcus ovatus obtido com o iniciador OPB-15. (M) marcador de peso molecular $1 \mathrm{~Kb}$ Ladder (Invitrogen). Indivíduos A-8 a A-13 (RS); A-14 (SC); A-15 a A-17 (PR) e A-18 a A-20 (RJ).

Figure 1. Pattern of fragments amplified by PCR-RAPD in individuals of Tectococcus ovatus obtained with primer OPB-15. (M) $1 \mathrm{~Kb}$ Ladder (Invitrogen) molecular weight marker. Individuals A-8 to A-13 (RS); A-14 (SC); A-15 to A-17 (PR) and A-18 to A-20 (RJ). 


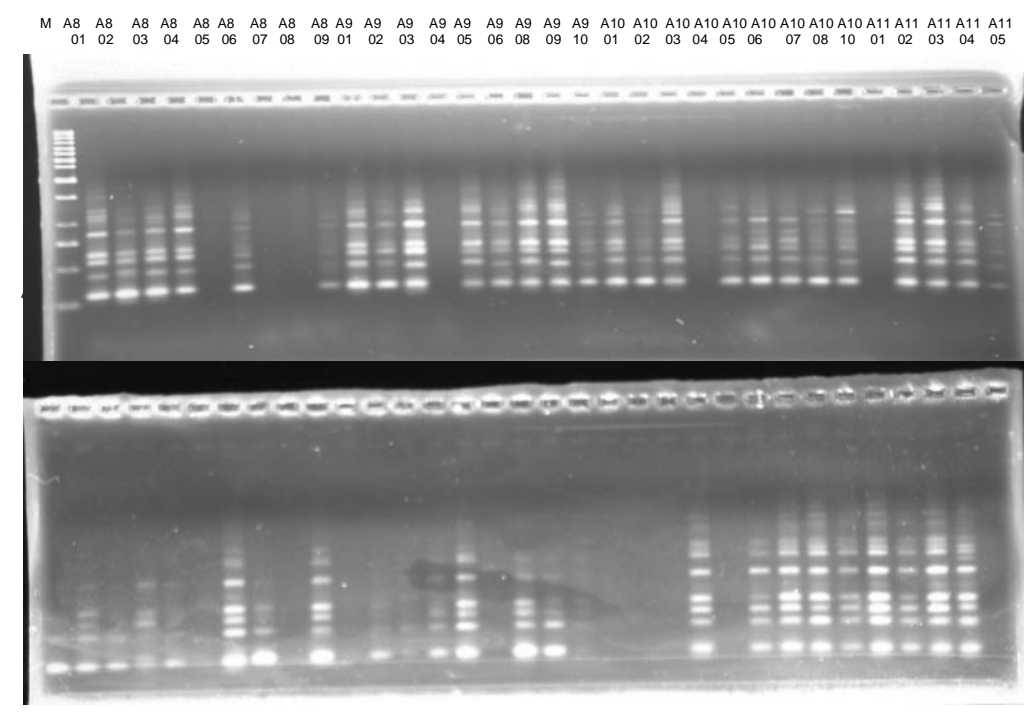

Figura 2. Padrão dos fragmentos amplificados por meio de PCR-RAPD em indivíduos de Tectococcus ovatus obtido com o iniciador 23L. (M) marcador de peso molecular $1 \mathrm{~Kb}$ Ladder (Invitrogen). Indivíduos A-8 a A-13 (RS); A-14 (SC); A-15 a A-17 (PR) e A-18 a A-20 (RJ).

Figure 2. Pattern of fragments amplified by PCR-RAPD in individuals of Tectococcus ovatus obtained with primer 23L. (M) $1 \mathrm{~Kb}$ Ladder (Invitrogen) molecular weight marker. Individuals A-8 to A-13 (RS); A-14 (SC); A-15 to A-17 (PR) and A-18 to A-20 (RJ).

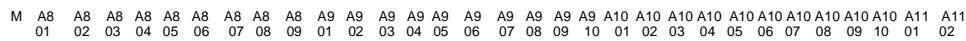

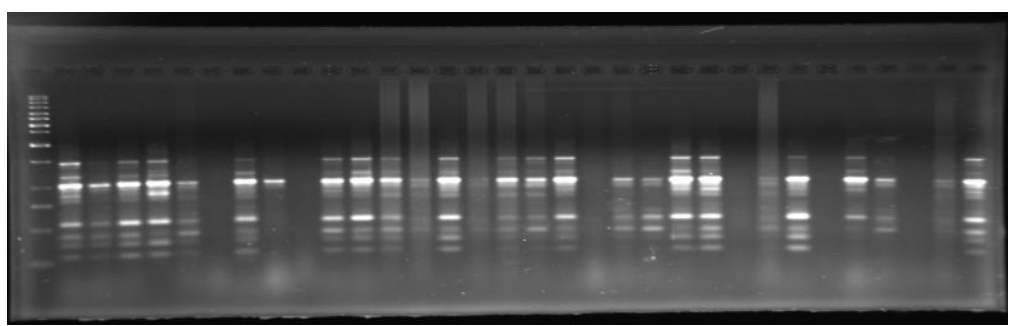

M A11 A11 A11 A11 A11 A11 A11 A11 A12 A12 A12 A12A12 A12 A12 A12 A12 A12 A13 A13A13 A13 A14 A14 A14 A14 A14 A14 A14 A14 A14

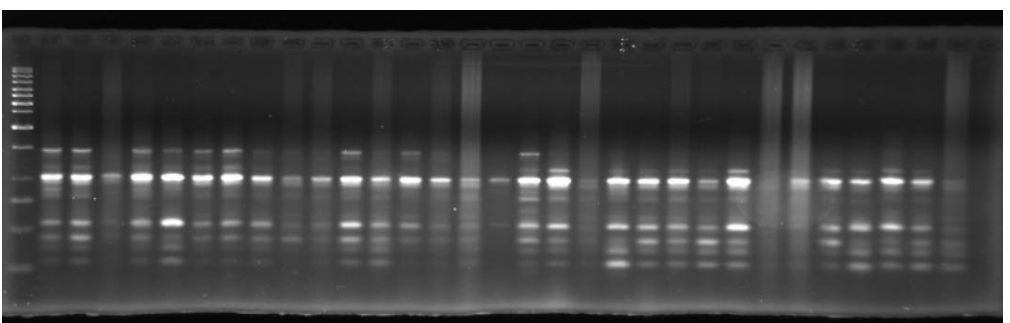

Figura 3. Padrão dos fragmentos amplificados por meio de PCR-RAPD em indivíduos de Tectococcus ovatus obtido com o iniciador OPB-6. (M) marcador de peso molecular $1 \mathrm{~Kb}$ Ladder (Invitrogen). Indivíduos A-8 a A-13 (RS); A-14 (SC); A-15 a A-17 (PR) e A-18 a A-20 (RJ).

Figure 3. Pattern of fragments amplified by PCR-RAPD in individuals of Tectococcus ovatus obtained with primer OPB-6. (M) $1 \mathrm{~Kb}$ Ladder (Invitrogen) molecular weight marker. Individuals A-8 to A-13 (RS); A-14 (SC); A-15 to A-17 (PR) and A-18 a A-20 (RJ). 

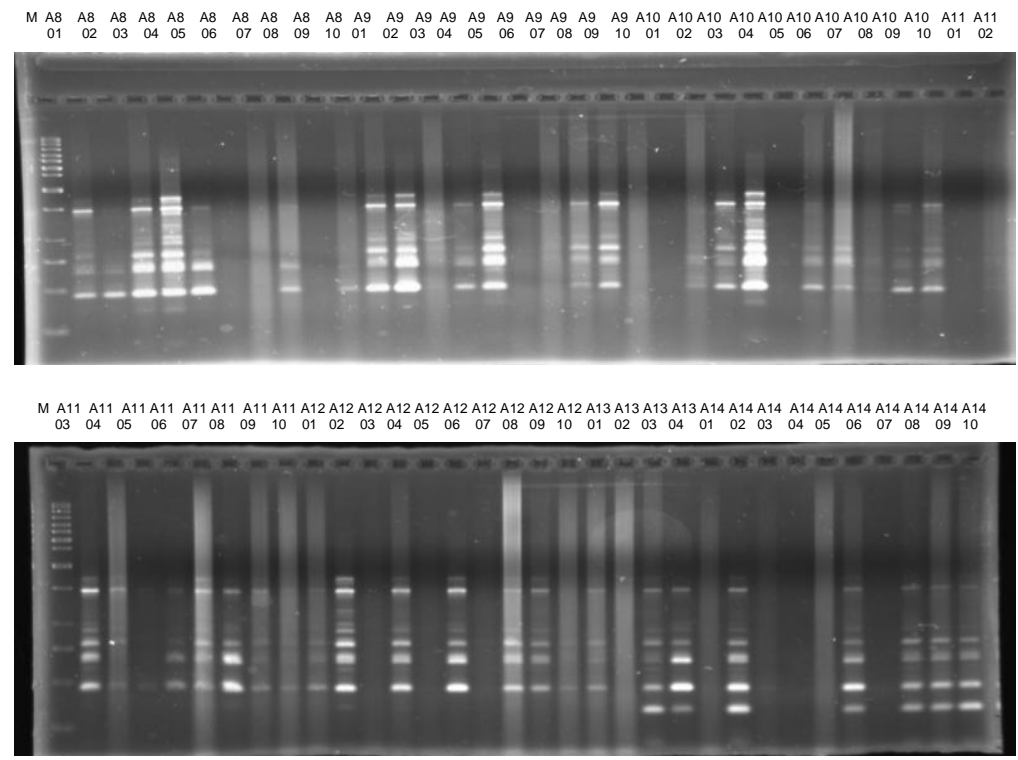

Figura 4. Padrão dos fragmentos amplificados por meio de PCR-RAPD em indivíduos de Tectococcus ovatus obtido com o iniciador OPM. (M) marcador de peso molecular $1 \mathrm{~Kb}$ Ladder (Invitrogen). Indivíduos A-8 a A-13 (RS); A-14 (SC); A-15 a A-17 (PR) e A-18 a A-20 (RJ).

Figure 4. Pattern of fragments amplified by PCR-RAPD in individuals of Tectococcus ovatus obtained with primer OPM. (M) $1 \mathrm{~Kb}$ Ladder (Invitrogen) molecular weight marker. Individuals A A-8 to A-13 (RS); A-14 (SC); A-15 to A-17 (PR) and A-18 to A-20 (RJ).

É possível verificar marcadores fixados em amostras de uma mesma localidade. Os marcadores de peso molecular $1070 \mathrm{pb}, 1214 \mathrm{pb}$ e 1286 do iniciador 23L amplificaram somente os indivíduos provenientes do Rio de Janeiro. Essas informações também podem ser observadas na análise através do método UPGMA, que revelou um agrupamento específico para esses indivíduos. É possível observar uma diferenciação genética de $24 \%$ (= 76\% similaridade) em relação às demais populações. É possível ainda observar no dendrograma uma pequena variação genética entre os indivíduos pertencentes a uma mesma população.

Uma observação deve ser feita aos indivíduos coletados no Paraná, pois eles foram extraídos de galhas encontradas na espécie Psidium ovale. A utilização desse material nas análises teve como objetivo verificar a existência de um padrão genético diferente do encontrado nas fêmeas extraídas de Psidium cattleianum. Esses indivíduos geraram marcadores em grande parte semelhantes aos encontrados nos outros indivíduos analisados, e, de acordo com os resultados obtidos até o momento, os insetos encontrados em $P$. ovale apresentam o mesmo padrão genético dos insetos encontrados em $P$. cattleianum, ou seja, as duas espécies são atacadas por Tectococcus ovatus. Seria prematuro afirmar a existência ou não de um padrão diferenciado nesses indivíduos, devido ao número reduzido de iniciadores utilizados nas análises, bem como devido ao número de procedências amostradas, já que indivíduos de $P$. ovale atacados por $T$. ovatus foram encontrados apenas na localidade dos Mananciais da Serra no Paraná. Para tanto, fazem-se necessárias novas análises de PCR-RAPD com um número maior de iniciadores e mais procedências de $P$. ovale.

Apesar dos quatro iniciadores de sequência curta estudados terem gerado marcadores com $96 \%$ de polimorfismo, não podemos afirmar que existe um alto nível de variabilidade genética entre as populações de T. ovatus estudadas. Essa afirmação fica mais clara ao observarmos os índices de variabilidade e similaridade no dendrograma apresentado na figura 5.

Uma hipótese a ser levantada para explicar o polimorfismo variável gerado entre os indivíduos pode estar relacionada à alta especificidade do agente de controle biológico T. ovatus ao gênero Psidium.

A investigação do grau de especificidade ao hospedeiro é a operação mais importante em projetos de controle biológico de plantas invasoras. Os resultados demonstraram que o agente se mostrou específico a $P$. cattleianum, uma vez que não houve ataque a nenhuma outra espécie vegetal pelo inseto (VITORINO et al., 2007). 


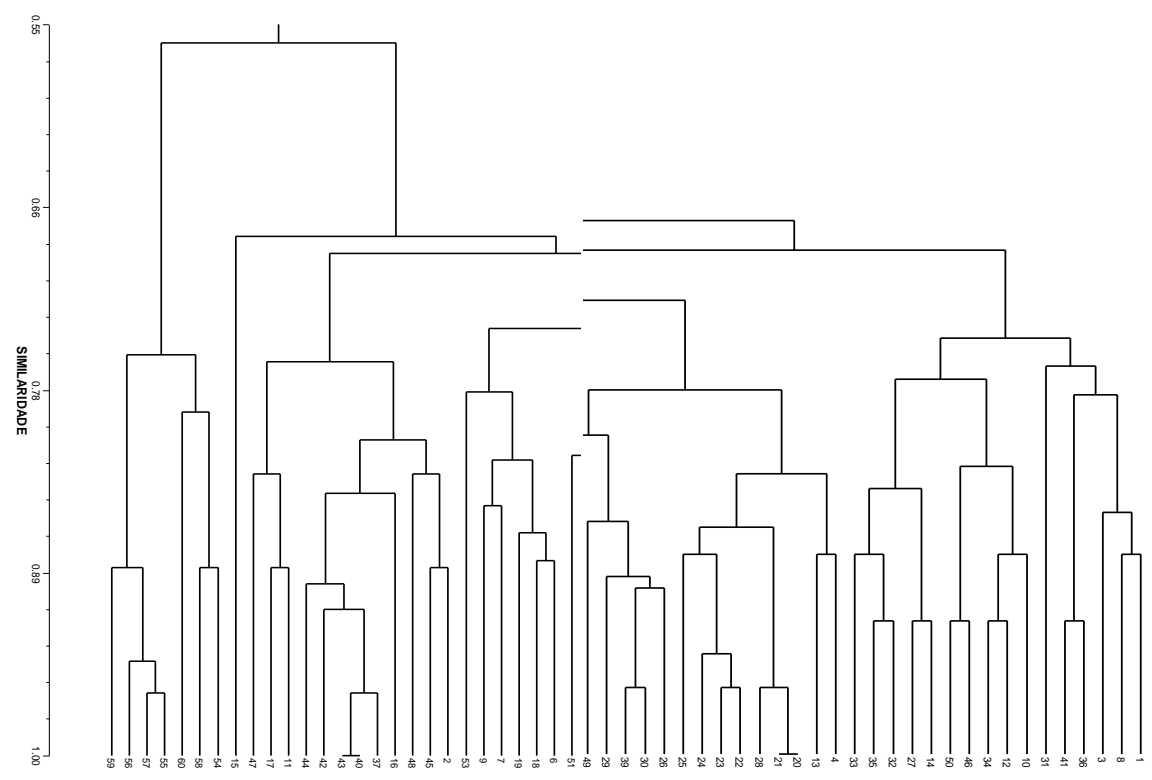

Figura 5. Dendrograma de variabilidade genética construído a partir das bandas mais frequentes nas amostras de Tectococcus ovatus Hempel, 1900 (Heteroptera: Eriococcidae) obtidas por meio da técnica PCR-RAPD, 2008.

Figure 5. Dendrogram constructed from genetic variability of the most frequently bands in samples of Tectococcus ovatus Hempel, 1900 (Heteroptera: Eriococcidae) obtained by PCR-RAPD.

Para Calado (2005), o polimorfismo observado entre indivíduos pode estar associado ao tipo de reprodução exibido pelas espécies, tendo em vista que a reprodução sexuada constitui-se num dos principais mecanismos para produzir indivíduos geneticamente diferentes.

De acordo com os dados levantados por Vitorino (1995), em insetos coletados no Paraná, a reprodução de $T$. ovatus pode ocorrer de duas formas, sexuada e assexuada (partenogenética), conforme a época do ano. A reprodução sexuada ocorreria de novembro a fevereiro, e a reprodução assexuada ocorreria de março a outubro.

É possível observar que, com exceção dos indivíduos coletados no Rio de Janeiro, todos os outros indivíduos foram coletados em épocas do ano onde a reprodução é considerada sexuada (Tabela 3).

Tabela 3. Número de indivíduos utilizados nas análises por área e data de coleta.

Table 3. Number of individuals used in the analysis by area and collection dates.

\begin{tabular}{lccccc}
\hline Estado & Município & Esp. & Código & Data coleta & N. indivíduos \\
\hline RS & Tramandaí & P.c. & A-11 & $07 / 04 / 2006$ & 8 \\
RS & Tramandaí & P.c. & A-12 & $07 / 04 / 2006$ & 8 \\
RS & Tramandaí & P.c. & A-13 & $08 / 04 / 2006$ & 3 \\
SC & Sombrio & P.c. & A-8 & $04 / 04 / 2006$ & 5 \\
SC & Sombrio & P.c. & A-9 & $04 / 04 / 2006$ & 6 \\
SC & Sombrio & P.c. & A-10 & $05 / 04 / 2006$ & 6 \\
SC & Baln. Camboriú - Estaleiro & P.c. & A-14 & $20 / 01 / 2007$ & 6 \\
PR & Piraquara - Mananciais da Serra & P.o. & A-15 & $04 / 12 / 2006$ & 6 \\
PR & Piraquara - Mananciais da Serra & P.o. & A-16 & $04 / 12 / 2006$ & 1 \\
PR & Piraquara - Mananciais da Serra & P.o. & A-17 & $04 / 12 / 2006$ & 1 \\
RJ & Campos dos Goytacazes - & P.c. & A-20 & $15 / 07 / 2008$ & 7 \\
\hline Total de indivíduos analisados & & & \\
\hline
\end{tabular}


No caso específico da população coletada no Rio de Janeiro, essa informação deixa algumas dúvidas, pois as coletas foram realizadas no mês de julho, levando-nos a considerar que todos os indivíduos dessa população seriam idênticos, devido à reprodução assexuada.

De acordo com os resultados apresentados, foi possível verificar a existência de polimorfismo entre os indivíduos dessa população. Essa informação nos conduz ao levantamento de hipóteses, como a ocorrência de uma reprodução sexuada fora de época ou que as populações amostradas não eram oriundas de reprodução assexuada, conduzindo, assim, a realização de estudos mais específicos quanto à época de aparecimento dos machos nessa área específica de coleta.

Por não existirem trabalhos relativos ao tema referentes à elucidação da variabilidade genética entre e dentro das populações de T. ovatus nas áreas estudadas, não foi possível fazer comparações com resultados anteriormente obtidos.

\section{CONCLUSÕES}

- Os iniciadores OPM, OPB-6, OPB-15 e 23L mostraram-se eficientes em determinar a variabilidade genética entre e dentro das diferentes populações de Tectococcus ovatus analisadas, revelando um nível variável de polimorfismo.

- Verificou-se a presença de marcadores fixados em amostras de uma mesma localidade. Os marcadores de peso molecular $1070 \mathrm{pb}, 1214 \mathrm{pb}$ e 1286 do iniciador 23L amplificaram somente os indivíduos provenientes do Rio de Janeiro.

- No dendrograma apresentado, foi possível observar a formação de dois grupos, A e B, e suas subdivisões, apresentando uma variabilidade genética de $44 \%$. No grupo A ficaram agrupados somente os indivíduos do Rio de Janeiro, demonstrando a existência de um padrão genético diferenciado dos demais indivíduos pertencentes às outras populações. De acordo com as informações apresentadas, essa diferenciação genética não se mostrou suficiente para que se possa afirmar que esses indivíduos são distintos dos demais.

- Não foi encontrado um padrão genético diferenciado nas populações de Tectococcus ovatus coletadas em Psidium ovale. Esses indivíduos geraram marcadores em grande parte semelhantes aos encontrados nos indivíduos extraídos de Psidium cattleianum, levando-nos a concluir que se trata de uma mesma espécie galhadora, tanto para Psidium ovale como para Psidium cattleianum.

- A identificação e confirmação da existência de variabilidade genética nas diferentes populações de Tectococcus ovatus analisadas por meio de características moleculares auxiliou na compreensão da relação do inseto com a espécie Psidium cattleianum, gerando informações importantes para o programa de controle biológico.

- Pelos resultados obtidos nos ensaios de PCR-RAPD, foi possível concluir que, apesar do polimorfismo encontrado entre e dentro das diferentes populações de $T$. ovatus analisadas, a princípio não existe um padrão genético diferenciado que faça com que seja necessário associar o local de origem do inseto com o local de origem da planta.

- O baixo nível de polimorfismo apresentado na maioria dos indivíduos analisados demonstra que, independentemente da procedência de T. ovatus, ele poderá ser usado para o controle de qualquer procedência de $P$. cattleianum no Havaí.

\section{REFERÊNCIAS}

CALADO, D. C. Polimorfismos em Anopheles cruzii Dyar \& Knab, 1908 detectados através de marcadores moleculares (RAPD E RFLP) e comparação com Anopheles bellator Dyar \& Knab, 1906 e Anopheles homunculus Komp, 1937(Diptera, Culicidae, Anophelinae) 2005. 156 f. Tese de Doutorado, Pós-Graduação em Ciências Biológicas, Área de Concentração em Entomologia da Universidade Federal do Paraná, Curitiba, 2005. Disponível em: 〈http://dspace.c3sl.ufpr.br/dspace/bitstream/1884/1433/1/dcalado.pdf〉. Acesso em: 31/04/2006.

CHEUNG, W. Y.; HUBERT, N.; LANDRY, B. S. A simple and rapid DNA micro extraction method for plant, animal, and insect suitable for RAPD and other PCR analyses. Technical Trip, v. 3, p. 69 - 70, 1993.

JACCARD, P. Nouvelles recherches sur la distribuitin florale. Bull. Soc. Vaudoise Sc. Nat. 44: 223 $270,1908$. 
LEGRAND, C. D.; KLEIN, R. M. Mirtaceae: Gênero 16: Psidium. In: REITZ, P. R. Flora ilustrada catarinense. Itajaí: Herbário Barbosa Rodrigues, 1977.

NASCIMENTO, C. P.; SILVA, M. Atlas geográfico do Médio Vale do Itajaí-SC: Curso de Geografia. FAED/UDESC. Disponível em: <http://www.faed.udesc.br/geolab/goesc.htm>. Acesso em: 17/04/2006.

PATERSON, I. D.; DOWNIE; D. A.; HILL, M. P. Using molecular methods to determine the origin of weed populations of Pereskia aculeate in South Africa and its relevance to biological control. Biological Control, Elsevier, v. 48, p. 84 - 91. 2009.

ROHLF, F. J. NTSYS-PC. Numerical taxonomy and multivariate analysis systems. Exeter Software, Applied Biostatistics, N. Y, 1992.

SILVA, G. B.; COSTA, N. L. Zoneamento da potencialidade agroflorestal das terras do município de Campos dos Goytacazes. IBGE. Salvador, 2006. Disponível em: <http://www.sbsaf.org.br/anais/2006/ solos_e_nutrição_de_plantas/trabalho107.doc>. Acesso em: 15/01/2009.

SMITH, C. W.; DENSLOW, J.; HIGHT, S. Pacific cooperative studies unit - University of Hawaii at Manoa, 2000. In: Workshop on biological control of invasive plants in native hawaiian ecosystems, Conservation Forum Hawaii Secretariat for Conservation Biology, 2002, Manoa, p. 108 - 116.

TUNISON, J. T. Element stewardship abstract for Psidium cattleianum. The Nature Conservancy, 1991. Disponível em: <http://tncweeds.ucdavis.edu/esadocs/documnts/psidcat.pdf>. Acesso em: 18/04/2006.

VITORINO, M. D. Aspectos biológicos e de especificidade de Tectococcus ovatus HEMPEL, 1900 (Heteroptera: Eriococcidae) para o controle biológico do araçazeiro Psidium catlleianum SABINE, 1821. 1995. 55 f. Dissertação (Mestrado em Ciências Florestais) - Setor de Ciências Agrárias, Universidade Federal do Paraná, Curitiba, 1995.

VITORINO, M. D.; PEDROSA-MACEDO, J. H.; SMITH, C. W. The Biology of Tectococcus ovatus Hempel (Heteroptera: Euriococcidae) and its potential as a biocontrol agent of Psidium cattleianum (Myrtaceae). In: X International symposium on biological control of weeds, 1999, Montana: Neal R. Spencer, 2000. p. 651 - 657.

VITORINO, M. D.; BUSS, A. L.; ZADROZNY, L. E. C. R; VITORINO, J. C. Biologia e potencial de Tectococcus ovatus Hempel, 1900 (Hemyptera: Eriococcidae), indutor da galha da folha do araçazeiro. In: PEDROSA-MACEDO, J. H.; DAL MOLIN, A.; SMITH, C. W. O araçazeiro: Ecologia e controle biológico. Curitiba: FUPEF do Paraná, 2007.

WEIR, B. S. Genetic Date Analysis. Sinauer Associates, Sunderland, 230 p., 1990.

WILliamS, D. A.; OVERHOLT, W. A.; CUDA, J. P.; HUGHES, C. R. Chloroplast and microsatellite DNA diversities reveal the introduction history of brazilian peppertree (Schinus terebionthifolius) in Florida. In: Molecular Ecology. Florida, n. 14, p. 3643 - 3656, 2005. 